\title{
Espécies de Cladonia P. Browne (Cladoniaceae, Ascomycota) dos Supergrupos Cocciferae, Crustaceae e Perviae em restingas e costões rochosos dos estados do Paraná e de Santa Catarina, Brasil
}

\author{
Emerson Luiz Gumboski ${ }^{1,2}$ e Sionara Eliasaro ${ }^{1}$
}

Recebido em 15/09/2011. Aceito em 18/05/2012

\begin{abstract}
RESUMO
(Espécies de Cladonia P. Browne (Cladoniaceae, Ascomycota) dos Supergrupos Cocciferae, Crustaceae e Perviae em restingas e costões rochosos dos estados do Paraná e de Santa Catarina, Brasil). Pouco se conhece das espécies de Cladonia que ocorrem nos estados do Paraná e de Santa Catarina. Informações sobre a ocorrência de liquens em restingas são muito escassas e não há qualquer registro para costões rochosos. O objetivo do trabalho foi realizar um levantamento intensivo das espécies de Cladonia presentes em áreas de restingas e costões rochosos presentes nos estados do Paraná e de Santa Catarina, sul do Brasil. Foram encontradas nove espécies pertencentes aos Supergrupos Cocciferae, Crustaceae e Perviae, sendo que Cladonia squamosa é nova citação para o Paraná e C. palmicola para Santa Catarina. Todas as espécies encontradas ocorrem em restingas e sete delas também em costões rochosos. São apresentadas chave de identificação, descrições, comentários e ilustrações.
\end{abstract}

Palavras-chave: Fungos liquenizados, litoral, taxonomia

\begin{abstract}
(Species of Cladonia P. Browne (Cladoniaceae, Ascomycota), of Supergroup Cocciferae, Crustaceae and Perviae, from restinga vegetation and rocky shores of Paraná and Santa Catarina, Brazil). Little is known about the species of Cladonia that occur in the states of Paraná and Santa Catarina, in southern Brazil. Information about the occurrence of lichens in restinga (a type of coastal vegetation in Brazil) is very scarce and there are no records from rocky shores. The main goal of the present work was to make an intensive survey of Cladonia species that grow in restinga and on the rocky shores of this region. Nine species belonging to Supergroups Cocciferae, Crustaceae and Perviae were found, and two of them were new records: Cladonia squamosa for Paraná and C. palmicola for Santa Catarina. All of the species recorded occur in restinga and seven of them are also found along rocky shores. An identification key, descriptions, comments and illustrations are provided.
\end{abstract}

Key words: Coast, lichenized fungi, taxonomy

\section{Introdução}

Cladonia P. Browne é o maior dos 12 gêneros reconhecidos por Stenroos et al. (2002a) para a família Cladoniaceae, e possui atualmente mais de 400 espécies (Stenroos et al. 2002a) conhecidas em todo o mundo. De acordo com Stenroos et al. (2002b), o gênero pode ser dividido em quatro Supergrupos: Cladonia, Perviae, Cocciferae e Crustaceae.

Segundo os estudos filogenéticos realizados por Stenroos et al. (2002b), as seções utilizadas por Ahti (2000) não apresentaram suporte filogenético e uma nova classificação provisória, a qual divide o gênero em quatro Supergrupos e que será seguida neste trabalho, foi sugerida pelos autores, a saber: o Supergrupo Cladonia possui o maior número de taxa, o mais bem representado no Brasil, e inclui espécies pertencentes às Seções Ascyphiferae, Helopodium e Cladonia sensu Ahti (2000); o Supergrupo Perviae é formado basicamente pelas espécies da Seção Perviae sensu Ahti (2000) incluindo Cladonia piedadensis Ahti, C. metaminiata S. Stenroos \& Ahti e C. perforata A. Evans, e excluindo C. variegata Ahti e C. bahiana Ahti; o Supergrupo Cocciferae continua tal como a Seção Cocciferae sensu Ahti (2000); e o Supergrupo

\footnotetext{
${ }^{1}$ Universidade Federal do Paraná, Departamento de Botânica, Laboratório de Liquenologia, Curitiba, PR, Brasil

${ }^{2}$ Autor para correspondência: emerson_gumboski@yahoo.com.br
} 
Crustaceae inclui o gênero Cladina, a seção Uncialis sensu Ahti (2000) e também Cladonia albofuscescens Vain.

Pouco se conhece das espécies de Cladonia que ocorrem nos estados do Paraná e Santa Catarina. Os primeiros registros para Santa Catarina foram feitos por Müller (1891a, b). Marcelli (1992) citou duas espécies para Santa Catarina, $C$. furfuracea Vain. e C. subsquamosa Kremp.. Osorio (1997) registrou a ocorrência de C. ahtii Stenroos, C. ceratophylla (Sw.) Spreng. e C. pityrophylla Nyl.

Os primeiros registros de Cladonia para o Paraná foram feitos somente no ano de 1995, com Ahti \& Marcelli (1995) mencionando C. fissidens Ahti \& Marcelli e C. verticillaris (Raddi) Fr. para ambientes de planalto.

Ahti (2000) registrou 107 espécies de Cladonia para o Brasil, dentre as quais 29 são encontradas no Paraná e 33 em Santa Catarina. Destas, apenas sete espécies foram registradas para restingas do Paraná e dez para Santa Catarina.

Marcelli (1998) demonstrou a necessidade de estudos sobre os liquens que ocorrem neste ambiente relatando que apenas 25 espécies foram citadas para todos os costões do litoral brasileiro, mas que ao menos 200 são esperadas. Recentemente, estudos envolvendo a família Parmeliaceae no litoral de São Paulo (Benatti 2005; Marcelli et al. 2008; Marcelli \& Benatti 2008, 2010a, b) citaram várias espécies que ocorrem em costões rochosos, contribuindo significativamente para o conhecimento deste ambiente. No entanto, antes da recente publicação de Cladonia litoralis Gumboski \& Eliasaro (Gumboski \& Eliasaro 2011a) não havia qualquer registro de exemplares de Cladonia para costões rochosos do Paraná e de Santa Catarina.

\section{Material e métodos}

As coletas foram realizadas em restingas e costões rochosos selecionados em onze cidades ao longo do litoral dos estados do Paraná e de Santa Catarina seguindo a metodologia descrita em Brodo et al. (2001). Em laboratório, os materiais foram secos em temperatura ambiente, herborizados e logo após incorporados ao Herbário UPCB da Universidade Federal do Paraná. Materiais adicionais de outras localidades também foram utilizados para comparações. As análises morfológicas foram realizadas sob microscópio estereoscópico (20-50X) e para as análises anatômicas, cortes feitos à mão livre foram observados sob microscópio fotônico (400-1000X), ambos com ocular dotada de retículo graduado. Para a identificação de metabólitos secundários de importância taxonômica foram utilizados: testes de coloração (K, C e KC) de córtex e medula segundo Taylor $(1967,1968)$, observação do talo sob lâmpada UV (Taylor 1967, 1968) e cromatografia em camada delgada (CCD) seguindo Culberson \& Ammann (1979) e Elix \& Ernst-Russell (1993).

\section{Resultados e discussão}

Foram encontradas nove espécies, sendo que Cladonia squamosa (Scop.) Hoffm. é uma nova citação para o Paraná e C. palmicola Ahti \& Fleig uma nova citação para Santa Catarina. Três espécies são do Supergrupo Cocciferae: Cladonia ahtii S. Stenroos, C. didyma (Fée) Vain. e C. macilenta Hoffm.; cinco do Supergrupo Perviae: C. crispatula (Nyl.) Ahti, C. palmicola, C. polystomata Ahti \& Sipman, C. sphacelata Vain. e C. squamosa; e apenas uma do Supergrupo Crustaceae: Cladonia confusa R. Sant..

Das nove espécies encontradas, sete ocorrem no Paraná e oito e Santa Catarina. Cladonia ahtii e C. palmicola foram encontradas somente em Santa Catarina, enquanto que $C$. sphacelata foi encontrada somente no Paraná. Todas as espécies ocorrem em restingas e apenas sete em costões rochosos, sendo que Cladonia ahtii e C. palmicola foram encontradas apenas em restingas (Tab. 1).

Cladonia confusa e C. crispatula foram as espécies mais frequentemente encontradas nas restingas, formando vários aglomerados similares a tapetes forrando o solo do ambiente. Em costões rochosos, no entanto, estas espécies são muito raras e não formam extensos tapetes. Cladonia didyma é a espécie mais comum em costões, embora geralmente não forme grandes aglomerados.

Em geral, exemplares da mesma espécie encontrados em ambos os ambientes apresentaram uma coloração um pouco mais escura quando em costões rochosos, onde formando colônias menores e com poucos podécios ao serem comparados aos exemplares ocorrentes em restingas.

\section{Chave artificial para as espécies de Cladonia dos Supergrupos Cocciferae, Crustaceae e Perviae encontradas em restingas e costões rochosos do Paraná e de Santa Catarina.}

1. Esquâmulas primárias arredondadas, sorediadas na margem 1. C. ahtii

1. Esquâmulas primárias ausentes ou, quando presentes, laciniadas e sem sorédios nas margens

2. Podécios com grânulos e/ou sorédios

3. Perfurações axilares ausentes

4. Superfície com sorédios e esquâmulas, estereoma raramente exposto.. 5. C. macilenta

4. Superfície com grânulos e esquâmulas, estereoma frequentemente exposto 4. C. didyma

3. Perfurações axilares presentes

5. Superfície com muitos grânulos, estereoma raramente exposto; $\mathrm{K}+$ amarelo vivo 6. C. palmicola

5. Superfície com poucos grânulos, estereoma frequentemente exposto; K-.. 9. C. squamosa 
2. Podécios sem grânulos e/ou sorédios

6. Podécio ecorticado, esquâmulas ausentes

6. Podécio corticado, esquâmulas presentes

7. Podécios esverdeados; K-

8. C. sphacelata

7. Podécios esbranquiçados a cinza azulados; $\mathrm{K}+$ amarelo vivo

8. Podécio com 4,0-13,0 $\mathrm{cm}$ de altura, muito ramificado.

3. C. crispatula

8. Podécio com $0,5-2,5 \mathrm{~cm}$ de altura, pouco ramificado

7. C. polystomata

Tabela 1. Ocorrência das espécies de Cladonia (Supergrupos Cocciferae, Crustaceae e Perviae) nos ambientes estudados baseada na quantidade de materiais coletados e observações de campo.

\begin{tabular}{lcccc}
\hline & Santa Catarina & & & Paraná \\
\hline Espécies & Costão rochoso & Restinga & Costão rochoso & Restinga \\
C. ahtii & - & Rara & - & Abundante \\
C. confusa & - & Abundante & Rara & Abundante \\
C. crispatula & Rara & Abundante & Frequente & Abundante \\
C. didyma & Frequente & Abundante & Rara & - \\
C. macilenta & Rara & Rara & Frequente & Frequente \\
C. palmicola & - & Rara & Frequente & Frequente \\
C. polystomata & Frequente & - & Rara & Frequente \\
C. sphacelata & - & - & & \\
C. squamosa & Rara & & & \\
\hline
\end{tabular}

1. Cladonia ahtii S. Stenroos, Ann. Bot. Fenn. 26: 252. 1989.

Fig. 1

TALO PRIMÁRIO: persistente, composto por esquâmulas, $0,5-1,5 \mathrm{~mm}$ de comprimento, $0,5-2,5 \mathrm{~mm}$ de largura, arredondadas, convexas, margem principalmente inteira, raramente recortada, não involuta, sem rizinas, sorediada, sorais lineares, estendendo até $0,5 \mathrm{~mm}$ na superfície inferior, sorédios farinosos, esbranquiçados a bege; superfície superior corticada, verde acinzentada a verde escurecida, lustrosa, verruculosa, às vezes com sorais orbiculares originados sobre as verrugas, até $0,6 \mathrm{~mm}$ de diâmetro, sorédios iguais aos da margem, sem pruína; superfície inferior ecorticada, suavemente aracnoide a quase lisa, branca; córtex (45-)100-230 $\mu \mathrm{m}$ de espessura, medula (50-)80-370 $\mu \mathrm{m}$ de espessura; picnídios raros, imaturos, laminais, marrom avermelhados, mucilagem ausente, conídios ausentes. TALO SECUNDÁRIO: ausente; discos himeniais raros, sésseis, laminais, vermelhos, em estágio inicial de desenvolvimento, ascósporos ausentes; picnídios ausentes.

Química: Testes de coloração: K-, C-, KC-, UV-. CCD: Ácido barbático, ácido didímico, ácido rodocladônico e uma substância não identificada com Rf C aproximado de 60.

Comentários: Cladonia ahtii pertence ao complexo C. miniata G. Mey. (Stenroos 1989) por apresentar o talo primário bem desenvolvido, córtex bastante espessado e discos himeniais vermelhos. Esta espécie caracteriza-se por apresentar o talo primário com medula sempre branca, esquâmulas primárias arredondadas e por produzir sorédios farinosos na margem (Stenroos 1989; Fleig et al. 1995) e na superfície superior das mesmas.

Na descrição desta espécie, Stenroos (1989) cita a presença de sorédios somente na margem das esquâmulas primárias. Contudo, os espécimes coletados na área de estudo bem como os exemplares adicionais estudados oriundos do planalto norte catarinense e da Serra do Mar paranaense, às vezes apresentam, além dos sorédios marginais, sorais orbiculares laminais na superfície superior. Stenroos (comunicação pessoal) mencionou que, até Cladonia ahtii ter sido descrita, poucos exemplares haviam sido estudados e tal característica só foi percebida posteriormente, com a análise de exemplares de diferentes lugares, e que esta característica será acrescentada na descrição da espécie na Monografia Mundial de Cladoniaceae, que está em preparação pelos autores Dr. Teuvo Ahti e Dra. Soili Stenroos.

Cladonia ahtii é similar a C. meridionalis Vain. por possuir as esquâmulas primárias com medula branca e sorediadas, porém, diferencia-se da mesma por apresentar esquâmulas primárias arredondadas e sorédios marginais, enquanto que $C$. meridionalis possui esquâmulas alongadas e sorédios ao longo de toda a superfície inferior (Ahti 2000).

Cladonia miniata pode produzir grânulos marginais nas esquâmulas primárias, lembrando sorédios. Contudo, possui a medula geralmente avermelhada, o que juntamente com os grânulos a diferencia de C. ahtii (Stenroos 1989).

Os exemplares da área de estudo apresentaram esquâmulas menores do que o mencionado por Stenroos (1989) 
e Ahti (2000). No entanto, em espécimes ocorrentes em regiões de altitude do Paraná e de Santa Catarina, observamos que os exemplares apresentam esquâmulas com as dimensões mencionadas por estes autores em conjunto com esquâmulas menores. Devido ao fato da área de estudo ser uma região bastante alterada e que sofre constantemente com ações antrópicas, como queimadas e pastejo de animais, os exemplares coletados deveriam estar em processo inicial de colonização, o que explicaria o tamanho reduzido.

Distribuição: Cladonia ahtii pode ser encontrada desde o nível do mar a até 900 metros de altitude (Ahti 2000). Conhecida na América do Sul para o Paraguai, Uruguai (Stenroos 1989) e Brasil. Citada para os estados da BA, MG (Ahti 2000), PR (Stenroos et al. 2002b), RS (Stenroos 1989), SC (Osorio 1997) e SP (Stenroos 1989).

Habitat: Encontrada em locais bem iluminados, sobre córtex de Butia sp. em restinga, frequentemente isolada, poucas vezes entremeada com alguns podécios de Cladonia subsquamosa. Fleig et al. (1995) também citam a presença da espécie em córtex de Butia sp., adicionando a presença também sobre córtex de Eucaliptus sp., restos vegetais e lenho apodrecido. O exemplar de Rio Negrinho, também corticícola, foi encontrado na base de um pinheiro, o que demonstra certa plasticidade da espécie com relação ao substrato colonizado.

Espécimes examinados: BRASIL. Santa Catarina: Laguna, restinga, $28^{\circ} 24^{\prime} \mathrm{S}, 48^{\circ} 47^{\prime} \mathrm{O}, 09 / \mathrm{III} / 2009$, E. Gumboski 755, 770, 771, 785 (UPCB), ibid., 25/VIII/2007, E. Gumboski 986 (UPCB).

Espécimes adicionais examinados: BRASIL. Paraná: Morretes, Serra da Graciosa, 20/XI/1999, T. Ahti \& S. Eliasaro 57582 (UPCB). Santa Catarina: Rio Negrinho, Rio dos Bugres, 01/V/2010, E. Gumboski 1894 (UPCB).

2. Cladonia confusa R. Sant., Ark. Bot. 30A(10): 13. 1942. Fig. 2

TALO PRIMÁRIO: ausente. TALO SECUNDÁRIO: $4,0-11,0 \mathrm{~cm}$ de altura, $0,3-0,7 \mathrm{~mm}$ de espessura, verde acinzentado a amarelo esverdeado, o mesmo talo pode apresentar variação na cor, às vezes a maior parte do talo apresenta coloração acinzentada enquanto a região apical apresenta uma coloração amarelo esverdeada, densamente ramificado, isotômico, principalmente tricotômico a dicotômico, ápices geralmente tetracotômicos, sem eixo principal distinto, entrenós com 1,5-3,0 mm de comprimento, ápices subulados, acifosos, perfurações presentes principalmente na parte superior do talo nas axilas próximas ao ápice, com 0,2-0,4 mm de diâmetro; superfície ecorticada, aracnoide, sem sorédios, grânulos e esquâmulas; medula 30-60 $\mu \mathrm{m}$ de espessura, estereoma hialino, 50-70 $\mu \mathrm{m}$ de espessura, canal central suavemente rugoso, $270-460 \mu \mathrm{m}$ de diâmetro; discos himeniais raros, apicais, marrom escurecidos, imaturos, ascósporos ausentes; picnídios apicais, ovoides, enegrecidos, mucilagem hialina, conídios filiformes levemente curvados, $4-6 \times 1 \mu \mathrm{m}$.
Química: Testes de coloração: K-, C-, KC- ou KC+ amarelo forte, UV-. CCD: Ácido perlatólico, ácido úsnico e uma substância não identificada com Rf C aproximado de 65.

Comentários: Cladonia confusa é caracterizada pela ausência do talo primário, pelo podécio densamente ramificado, ecorticado, sem qualquer produção de propágulos, com ramos apicais tricotômicos a politômicos sem um eixo principal distinto, perfurações axilares evidentes (Santesson 1942) e por produzir ácido perlatólico (Fleig et al. 1995).

Cladonia signata (Eschw.) Vain. é uma espécie similar por apresentar podécios densamente ramificados isotomicamente. Contudo, possui ramificações principalmente dicotômicas, geralmente sem perfurações axilares distintas e produz ácido fumarprotocetrárico, enquanto que $C$. confusa produz ácido perlatólico e, ocasionalmente, ácido úsnico.

Distribuição: Ocorre desde o nível do mar até 4045 metros de altitude (Ahti 2000). Possui uma ampla distribuição mundial, sendo encontrada na África (Swinscow \& Krog 1988), América do Norte, América Central (Ahti 1961) e América do Sul, na Argentina (Santesson 1942), Bolívia (Ahti 1961), Colômbia (Ahti 1961), Equador (Santesson 1942), Guiana (Sipman \& Aptroot 1992), Paraguai, Peru (Ahti 2000), Uruguai, Venezuela (Ahti 1961) e Brasil (Santesson 1942). Citada para os estados do AM (Ahti 2000), BA (Ahti 1961), ES (Ahti 2000), MG (Ahti 1961), PR (Ahti 2000), RJ (Santesson 1942), RS (Osorio \& Arbelo Martins 1980), RR (Ahti 2000), SC (Gumboski \& Eliasaro 2011b) e SP (Santesson 1942).

Habitat: Cladonia confusa é muito comum em restingas, sendo encontrada principalmente nas bordas de caminhos em áreas bem iluminadas, às vezes a pleno sol em restinga herbácea. Geralmente forma extensos tapetes com até $4 \mathrm{~m}^{2}$, como observado na restinga arbustiva do Parque Estadual do Acaraí (São Francisco do Sul, SC). Estes são constituídos de podécios cilíndricos cujos tufos apresentam ápices semiglobosos de até $5,0 \mathrm{~cm}$ de diâmetro cada, muito frequentemente entremeados com podécios de C. crispatula, e às vezes com podécios de C. subsquamosa, C. ochracea L. Scriba, C. didyma e C. subradiata (Vain.) Sandst. Foi raramente encontrada em costões rochosos, onde apresenta podécios geralmente com tamanhos menores, atingindo no máximo 5,0 $\mathrm{cm}$ de altura.

Espécimes selecionados examinados: BRASIL. Paraná:

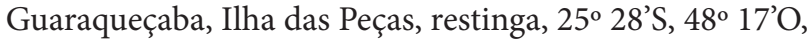
20/III/2010, E. Gumboski \& F. Beilke 1801, 1813 (UPCB); Paranaguá, Parque Estadual da Ilha do Mel, restinga, 25 31'S, 48 18'O, 29/III/2009, E. Gumboski \& S. Eliasaro 1499, 1562 (UPCB), ibid., costão rochoso na Praia de Fora, 27/ VIII/2009, 25 32'S, 48 17'O, E. Gumboski \& S. Eliasaro 1650, 1652 (UPCB); Pontal do Paraná, Pontal do Sul, restinga, 28/II/2008, M. Dal-Forno 542, 544 (UPCB); Matinhos, Parque Estadual Rio da Onça, restinga, 31/I/2004, J. Sonehara s.n. (UPCB 55607). Santa Catarina: Itapoá, Reserva Volta Velha, restinga, 20/IV/1998, Y. Grummt s.n. (UPCB 35499); São Francisco do Sul, Parque Estadual do 
Acaraí, restinga, $26^{\circ} 15^{\prime} \mathrm{S}, 48^{\circ} 31^{\prime} \mathrm{O}, 17 / \mathrm{III} / 2009$, E. Gumboski 800 (UPCB), ibid., Baia da Babitonga, Ilha dos Papagaios, 16/XI/2009, F. Woitexen s.n. (UPCB); Balneário Camboriú, Praia de Taquarinhos, restinga, 28/X/1994, M. Schatzmann s.n. (UPCB 55606); Florianópolis, Rio Ratones, restinga, 06/ IX/2009, L. Fernandes s.n. (UPCB).

3. Cladonia crispatula (Nyl.) Ahti, Lichenologist 9: 14. 1977.

Cladina rangiferina var. crispatula Nyl., Flora 52: 117. 1869. Fig. 3

TALO PRIMÁRIO: ausente. TALO SECUNDÁRIO: $4,0-13,0 \mathrm{~cm}$ de altura, $0,4-1,2 \mathrm{~mm}$ de espessura, cinza esbranquiçado a verde azulado, muito ramificado com eixo principal distinto, ramificação anisotômica, dicotômica, tricotômica, raramente tetracotômica sendo estas geralmente localizadas na porção apical, entre nós com $0,3-0,7 \mathrm{~cm}$ de comprimento, ápices subulados a capitados, acifosos, base não melanótica, mas às vezes apresenta coloração rósea, que também pode apresentar-se aleatoriamente no talo, perfurações axilares presentes com até $0,8 \mathrm{~mm}$ de diâmetro; superfície lisa a levemente rugosa, corticada areolada, sem sorédios e grânulos, esquâmulas ausentes ou presentes, às vezes abundantes principalmente em talos menores, com até 5,0 cm de altura, esquâmulas laciniadas, recortadas, até $3,0 \mathrm{~mm}$ de comprimento; córtex $12-45 \mu \mathrm{m}$ de espessura, medula 37-225 $\mu \mathrm{m}$ de espessura, estereoma hialino, 25-150 $\mu \mathrm{m}$ de espessura, canal central ranhurado e levemente papilado, 500-1000 $\mu \mathrm{m}$ de diâmetro; discos himeniais raros, apicais, amarronzados, imaturos, ascósporos ausentes; picnídios apicais, cilíndricos, negros, mucilagem avermelhada, conídios filiformes suavemente curvados, com 6-8 $8 \times 1 \mu \mathrm{m}$.

Química: Testes de coloração: K+ amarelo vivo, C-, KC-, UV-. CCD: Ácido tamnólico.

Comentários: Cladonia crispatula é caracterizada pelo talo moderadamente a muito ramificado, com eixo principal distinto de até $1,5 \mathrm{~mm}$ de espessura, axilas perfuradas, superfície corticada, lisa a levemente rugosa, sem sorédios e grânulos, e pela produção de ácido tamnólico (Ahti 1977; 2000; Fleig et al. 1995).

Segundo Ahti (1977; 2000), Cladonia rugicaulis Ahti também apresenta podécios muito ramificados, com eixo principal distinto, corticados, axilas perfuradas e produz ácido tamnólico. Contudo, em C. crispatula o podécio é mais delgado, com no máximo $1,5 \mathrm{~mm}$ de espessura, a superfície é lisa a suavemente rugosa e os ápices geralmente são corticados, enquanto que $C$. rugicaulis possui o podécio mais espesso, podendo chegar a 4,0 $\mathrm{mm}$ de espessura, com a superfície verruculosa principalmente próximo a base e ápices geralmente fibrilosos e sem córtex (Ahti 2000).

Cladonia furcata (Huds.) Schrad. também apresenta podécio ramificado com superfície corticada, lisa a rugosa e axilas geralmente perfuradas (Ahti \& Hammer 2002; Burgaz \& Ahti 2009), porém, apresenta o córtex principalmente contínuo e produz ácido fumarprotocetrárico.
Distribuição: Segundo Ahti (2000), esta espécie ocorre somente no Brasil, Paraguai e Uruguai, desde o nível do mar até 2000 metros de altitude. No Brasil é citada para os estados da BA, ES, MG, PR (Ahti 2000), RJ (Nylander 1869 - como Cladina rangiferina var. crispatula Nyl.), RS (Osorio \& Fleig 1986), SC (Gumboski \& Eliasaro 2011b) e SP (Marcelli 1990).

Habitat: Cladonia crispatula é bastante comum em restingas e rara em costões rochosos. Os podécios formam aglomerados com aspecto pulviniforme com até $30 \mathrm{~cm}$ de diâmetro, colonizando áreas de borda de mata ou trilhas bem iluminadas. É comumente encontrada também a pleno sol em restingas herbáceas. Embora Fleig et al. (1995) tenham citado a ocorrência da espécie sobre rocha, os materiais coletados em costões rochosos estavam sobre uma camada de sedimentos arenosos e não diretamente sobre a rocha. Todos os materiais coletados são terrícolas, encontrados sobre solo arenoso. É comum a formação de extensos tapetes desta espécie juntamente com podécios de C. confusa, principalmente na borda de restingas arbustivas (ver comentários em C. confusa).

Espécimes selecionados examinados: BRASIL. Paraná: Guaraqueçaba, Ilha das Peças, restinga, $25^{\circ} 28^{\prime} \mathrm{S}, 48^{\circ} 17^{\prime} \mathrm{O}$, 20/III/2010, E. Gumboski \& F. Beilke 1799, 1836 (UPCB); Paranaguá, Parque Estadual da Ilha do Mel, costão rochoso, $25^{\circ} 32^{\prime} \mathrm{S}, 48^{\circ} 17^{\prime} \mathrm{O}, 27 / \mathrm{VIII} / 2009$, E. Gumboski \& S. Eliasaro 1651, 1656, 1657 (UPCB), ibid., restinga $25^{\circ} 31^{\prime} \mathrm{S}, 48^{\circ} 18^{\prime} \mathrm{O}$, 27/VIII/2009, E. Gumboski \& S. Eliasaro 1577, 1579, 1608 (UPCB); Pontal do Paraná, beira do Rio Guaraguaçu, restinga, 02/VII/1999, A. Rocha Neto et al. s.n. (UPCB 55658); Matinhos, Ilha das Tartarugas, costão rochoso, $25^{\circ} 51^{\prime} \mathrm{S}, 48^{\circ}$ 32'O, 21/III/2010, E. Gumboski \& F. Beilke 1836 (UPCB). Santa Catarina: São Francisco do Sul, Morro João Dias, costão rochoso, $26^{\circ} 10^{\prime} \mathrm{S}, 48^{\circ} 31^{\prime} \mathrm{O}, 05 / \mathrm{III} / 2009$, E. Gumboski 687, 688, 689a (UPCB), ibid., Parque Estadual do Acaraí, restinga, $26^{\circ} 15^{\prime} \mathrm{S}, 48^{\circ} 31^{\prime} \mathrm{O}, 17 / \mathrm{III} / 2009$, E. Gumboski 801, 802, 878 (UPCB); Balneário Camboriú, Praia Taquarinhos, 28/X/1994, M. Schatzmann s.n. (UPCB); Laguna, restin-

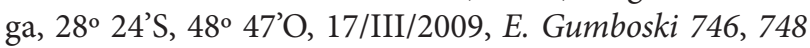
(UPCB).

4. Cladonia didyma (Fée) Vain., Acta Soc. Fauna Fl. Fenn. 4: 137.1887.

Scyphophorus didymus Fée, Essai Crypt. Écorc. 118: 101. 1825 [1824].

Fig. 4

TALO PRIMÁRIO: persistente, composto por esquâmulas, $0,7-2,0 \mathrm{~mm}$ de comprimento, $0,5-1,5 \mathrm{~mm}$ de largura, lobadas a laciniadas, inconspícuas, recortadas ou não, sem sorédios, margem lisa a pouco crenada, sem rizinas; superfície superior corticada, esverdeada a acinzentada, pouco a evidentemente lustrosa, lisa, sem pruína; superfície inferior ecorticada, aracnoide, branca; córtex com 10-30 $\mu \mathrm{m}$ de espessura, medula com 30-90 $\mu \mathrm{m}$ de espessura; picnídios ausentes. TALO SECUNDÁRIO: (0,5-)1,0-2,4 cm de altura, 
0,5-1,5 mm de espessura, esbranquiçados a pardacentos, geralmente simples, às vezes pouco ramificado com até cinco ramificações ocorrendo principalmente na metade superior, ápices subulados a capitados, acifosos, base não melanótica, porém, às vezes amarronzada e/ou com pigmentação amarelada, perfurações ausentes nas axilas, porém, com ocasional ruptura entre os discos himeniais em alguns talos bem desenvolvidos, deixando um pequeno espaço e expondo o canal central; superfície totalmente ecorticada e quase sem medula, lisa, às vezes pouco sulcada e velosa quando a medula está presente, sem sorédios, granulosa, porém alguns grânulos diminutos semelhantes a sorédios, geralmente com muitas esquâmulas ao longo do podécio, mas dispostas principalmente na porção basal e logo abaixo dos discos himeniais, esquâmulas laciniadas, recortadas ou não, com até $1,0 \mathrm{~mm}$ de comprimento; medula 0-20 $\mu \mathrm{m}$ de espessura, estereoma acinzentado a amarronzado, $100-142 \mu \mathrm{m}$ de espessura, canal central levemente ranhurado, 300-1100 $\mu \mathrm{m}$ de diâmetro; discos himeniais apicais, às vezes dispondo-se em grandes aglomerados, vermelhos a vermelho enegrecidos, ascósporos fusiformes, $10-16 \times 3-5 \mu \mathrm{m}$; picnídios ausentes.

Química: Testes de coloração: K-, C-, KC-, UV-. CCD: Ácido barbático, ácido didímico, ácido rodocladônico e duas substâncias não identificadas com $\mathrm{Rf} C$ aproximados de 60 e 75 .

Comentários: Cladonia didyma é caracterizada pelo podécio simples a pouco ramificado, acifoso, ecorticado, granuloso e esquamuloso, sem sorédios, disco himenial vermelho (Vainio 1887; Fleig et al. 1995) e por geralmente produzir ácido barbático juntamente com ácido didímico (Ahti 2000; Ahti \& Hammer 2002).

Cladonia macilenta Hoffm. é semelhante à $C$. didyma devido a ambas apresentarem podécios subulados a capitados, discos himeniais vermelhos e por produzirem ácido barbático e ácido didímico. Entretanto, C. didyma apresenta o estereoma geralmente exposto, com a presença de grânulos e esquâmulas, enquanto C. macilenta possui o podécio completamente coberto por sorédios farinosos, não deixando o estereoma exposto.

Quando Cladonia didyma não apresenta discos himeniais pode facilmente ser confundida com exemplares estéreis de C. furfuracea devido ao fato de ambas apresentarem podécios geralmente simples, com esquâmulas e estereoma exposto (Fleig et al. 1995). No entanto, C. didyma apresenta o podécio subulado, acifoso e produz ácido barbático e/ou ácido didímico, ao passo que C. furfuracea possui o podécio geralmente cifoso e produz ácido fumarprotocetrárico.

Segundo Fleig et al. (1995) e Ahti (2000), Cladonia didyma apresenta axilas fechadas, sem perfurações. Contudo, nos espécimes examinados, principalmente os bem desenvolvidos e com muitos discos himeniais, a presença de perfuração entre os discos foi comumente encontrada, fato também relatado por Vainio (1887). Isso ocorre devido ao rompimento do tecido himenial e não deve ser confundido como uma perfuração axilar.
Em alguns exemplares (E. Gumboski 481, 658, 666, 673, 675, E. Gumboski \& S. Eliasaro 1600, 1641, 1642, $1645 \mathrm{e}$ 1649) foram observados esquâmulas primárias mais espessadas e podécios menores com propágulos aparentemente distribuídos na região basal ou próximos ao ápice, bem como uma pequena diferença no tamanho dos ascósporos, além de uma pequena variação na produção de compostos secundários. Esses exemplares podem fazer parte de um complexo de espécies, porém, como em Cladonia algumas espécies apresentam uma grande plasticidade fenotípica e até mesmo química (e.g. Ahti 2000; Burgaz \& Ahti 2009), acreditamos que seja prudente manter esses exemplares sob a identificação de Cladonia didyma até que análises mais complexas possam esclarecer as relações filogenéticas entre os mesmos.

Distribuição: De acordo com Ahti (2000) ocorre desde o nível do mar até altitudes superiores a 3000 metros. Cladonia didyma é cosmopolita, podendo ser encontrada na Oceania, Ásia (Vainio 1887), África (Doidge 1950), América do Norte (Fulford 1937), América Central (Vainio 1887) e América do Sul, na Argentina (Grassi 1950 apud Calvelo \& Liberatore 2002), Bolívia (Ahti 2000), Chile (Crombie 1876 - como C. melanodes Nyl.), Colômbia, Equador (Ahti 2000), Guiana (Sipman 1990), Paraguai, Peru, Suriname, Trinidad e Tobago, Uruguai, Venezuela (Ahti 2000) e Brasil. Citada para os estados do AM, BA, DF, ES (Ahti 2000), MG (Vainio 1887), MT, PA, PR (Ahti 2000), PE (Ahti et al. 1993), RJ (Krempelhuber 1876 - como C. muscigena Eschw.), RN (Ahti et al. 1993), RR (Ahti 2000), RS (Spielmann 2006), RO (Ahti 2000), SC (Gumboski \& Eliasaro 2011b), SE (Ahti et al. 1993) e SP (Marcelli 1990).

Habitat: Comumente encontrada em restingas e costões rochosos da área de estudo. Nos costões os podécios adquirem um tom mais escuro e geralmente apresentam um número maior de esquâmulas do que nos exemplares presentes em restingas, floresta ombrófila submontana e estepes (espécimes adicionais examinados). Assim como citado por Fleig et al. (1995), a espécie coloniza lenho em decomposição, solo arenoso ou fina camada de sedimentos depositados em concavidades das rochas. Ocorre tanto em áreas bem iluminadas quanto em áreas mais sombreadas. Comumente encontrada entre podécios de Cladonia subsquamosa, C. subradiata, C. ochracea e C. ramulosa (With.) J. R. Laundon.

Espécimes selecionados examinados: BRASIL. Paraná: Guaraqueçaba, Ilha das Peças, restinga, 25/X/2003, C. G. Donha 1256, 1349 (UPCB); Paranaguá, Parque Estadual da Ilha do Mel, restinga, $25^{\circ} 31^{\prime} \mathrm{S}, 48^{\circ} 18^{\prime} \mathrm{O}, 27 / \mathrm{VIII} / 2009$, E. Gumboski \& S. Eliasaro 1547, 1551b, 1599, 1600 (UPCB),

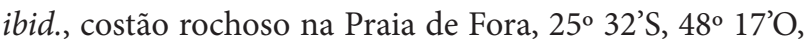
27/VIII/2009, E. Gumboski \& S. Eliasaro 1637, 1641, 1642, $1645,1646,1647,1648,1649$ (UPCB); Matinhos, Ilha das Tartarugas, costão rochoso, $25^{\circ} 51^{\prime} \mathrm{S}, 48^{\circ} 32^{\prime} \mathrm{O}, 21 / \mathrm{III} / 2010$, E. Gumboski \& F. Beilke 1834 (UPCB); Guaratuba, Barra do Saí, restinga, 05/XI/2004, A. C. Cervi \& J. M. Silva 8721 
(UPCB). Santa Catarina: São Francisco do Sul, Morro João Dias, costão rochoso, $26^{\circ} 10^{\prime} \mathrm{S}, 48^{\circ} 31^{\prime} \mathrm{O}, 05 / \mathrm{III} / 2009$, E. Gumboski 658, 666, 673, 675, 683, 685 (UPCB), ibid., Parque Estadual do Acaraí, restinga, $26^{\circ} 15^{\prime} \mathrm{S}, 48^{\circ} 31^{\circ} \mathrm{O}, 17 /$ III/2009, E. Gumboski 807, 810, 813 (UPCB); Bombinhas, Praia de Mariscal, costão rochoso, $26^{\circ} 13^{\prime} \mathrm{S}, 48^{\circ} 29^{\prime} \mathrm{O}, 19 /$ II/2010, E. Gumboski \& F. Beilke 1721, 1723, 1745 (UPCB).

Espécimes adicionais examinados: BRASIL. Rio Grande do Sul: Arroio do Sal, Praia Santa Rita, 20/I/1994, M. Fleig 6105 (ICN); Bagé, Casa de Pedra, 14 Km em vicinal paralela a BR 153, 03/XI/1989, M. Fleig 3914 (ICN).

\section{Cladonia macilenta Hoffm., Deutschl. Fl. 2: 126. 1796.} Fig. 5

TALO PRIMÁRIO: persistente, composto por esquâmulas, 0,3-0,6 mm de comprimento, $0,1-0,3 \mathrm{~mm}$ de largura, bastante próximas, às vezes chegando a formar um pequeno tapete contínuo, irregularmente lobadas, recortadas, sem sorédios, margem lisa a crenada, sem rizinas; superfície superior corticada, lisa, opaca, esbranquiçada a acinzentada, sem pruína; superfície inferior ecorticada, levemente velosa, branca; córtex 2,5-4,0 $\mu \mathrm{m}$ de espessura, medula 50-110 $\mu \mathrm{m}$ de espessura; picnídios ausentes. TALO SECUNDÁRIO: $(1,1-) 3,0-4,5(-10,0)$ $\mathrm{mm}$ de altura, 0,2-0,4 $\mathrm{mm}$ de espessura, esbranquiçados a levemente acinzentados, simples, ápices subulados, acifosos, porém pode apresentar um aspecto cifoide devido a formação e presença dos discos himeniais, base não melanótica, perfurações ausentes; superfície ecorticada, totalmente coberta por sorédios farinosos, sem grânulos e esquâmulas; medula $20-43 \mu \mathrm{m}$ de espessura, estereoma hialino a levemente amarelado, $50-118 \mu \mathrm{m}$ de espessura, canal central levemente verrucoso, 125-245 $\mu \mathrm{m}$ de diâmetro; discos himeniais apicais, geralmente ausentes ou imaturos, vermelhos, ascósporos ausentes; picnídios ausentes.

Química: Testes de coloração: $\mathrm{K}+$ amarelo vivo ou $\mathrm{K}+$ amarelo sujo, C-, KC-, UV-. CCD: Dois quimiotipos: $1-E$. Gumboski 786 produz ácido tamnólico sem outros compostos menores; 2 - ácidos barbático, didímico e rodocladônico, além de uma substância não identificada com $\mathrm{Rf} C$ aproximado de 75 e um pigmento com $\mathrm{Rf} C$ aproximado de 20.

Comentários: Cladonia macilenta é caracterizada pelas esquâmulas primárias persistentes, opacas, podécios simples, subulados, ecorticados, densamente cobertos por sorédios farinosos e pelo disco himenial vermelho (Vainio 1887; Fleig et al. 1995).

De acordo com Ahti \& Hammer (2002), os espécimes com ácido barbático e ácido tamnólico eram usualmente identificados como espécies distintas: Cladonia bacillaris (Ach.) Nyl. com ácido barbático e C. macilenta com ácido tamnólico. Entretanto, segundo Christensen (1987) e Ahti (2000), não há variações morfológicas relacionadas às variações químicas, considerando, portanto, os quimiotipos como pertencentes à mesma espécie. Concordamos com estes autores, pois observamos que o espécime que produz ácido tamnólico não apresentou diferenças morfológicas ou de hábitos que pudessem diferenciá-lo dos que produzem ácidos barbático e didímico. Também não foram encontradas diferenças morfológicas significantes entre os espécimes da área de estudo e os espécimes provenientes de Minas Gerais, Rio Grande do Sul e São Paulo.

Cladonia macilentoides Ahti \& Fleig é similar a $C$. macilenta por ambas apresentarem podécios subulados, ecorticados, densamente cobertos por sorédios e por produzirem ácido tamnólico. Contudo, Ahti (2000) menciona que C. macilenta apresenta podécios geralmente menores que $2,0 \mathrm{~cm}$ de altura, raramente atingindo $4,0 \mathrm{~cm}$ (os presentes na área de estudo atingiram $1,0 \mathrm{~cm}$ ), simples e com base não melanótica, enquanto que $C$. macilentoides apresenta podécios entre 3,0 e $5,0 \mathrm{~cm}$ de altura, geralmente pouco dicotomicamente ramificados e com base variando de suavemente a distintamente melanótica.

Cladonia macilenta pode ser confundida com C. didyma por possuírem podécios simples com discos himeniais vermelhos e por produzirem ácido barbático (ver comentários em Cladonia didyma).

Distribuição: Cosmopolita, ocorre desde o nível do mar até altitudes superiores a 3500 metros (Ahti 2000). É conhecida para a Oceania (Vainio 1887), Ásia (Sipman 1993), Europa (Crombie 1883), África (Müller 1884), América do Norte (Macoun 1902), América Central (Ahti 2000) e América do Sul, na Argentina (Müller 1889), Chile (Ahti \& Kashiwadani 1984), Colômbia, Equador, Paraguai, Uruguai, Venezuela (Ahti 2000) e Brasil (Vainio 1887). Citada para os estados do ES (Ahti 2000), MG (Vainio 1887), PR, RJ (Ahti 2000), RS (Osorio \& Fleig 1982), SC e SP (Ahti 2000).

Habitat: $\mathrm{Na}$ área de estudo Cladonia macilenta foi raramente encontrada, formando colônias bastante inconspícuas, isoladas, sempre sobre solo arenoso e serapilheira. Segundo Fleig et al. (1995), pode ainda ocorrer sobre lenho em decomposição ou fina camada de sedimentos sobre rocha.

Espécimes examinados: BRASIL. Paraná: Matinhos, Ilha das Tartarugas, costão rochoso, $25^{\circ} 51^{\prime} \mathrm{S}, 48^{\circ} 32^{\prime} \mathrm{O}$, 21/III/2010, E. Gumboski \& F. Beilke 1842 (UPCB). Santa Catarina: São Francisco do Sul, Morro da Enseada; costão rochoso, 26 13'S, 48 29'O, 28/IV/2008, E. Gumboski 132 (UPCB); Laguna, restinga, 28 $24^{\circ} \mathrm{S}, 48^{\circ} 47^{\prime} \mathrm{O}, 09 / \mathrm{III} / 2009$, E. Gumboski 786 (UPCB).

Espécimes adicionais examinados: BRASIL. Minas Gerais: Itamonte, Parque Nacional do Itatiaia, Estrada das Prateleiras, 17/III/1980, M. P. Marcelli \& K. Kalb 17465 (SP). São Paulo: Campos do Jordão, Parque Estadual de Campos do Jordão, Estrada para São José dos Alpes, 08/XII/1993, M. P. Marcelli, T. Ahti \& O. Yano 26073 (SP). Rio Grande do Sul: Torres, 12/X/1992, M. Fleig 4735 (ICN); Cambará do Sul, Itaimbezinho, 23/VII/1981, M. Fleig 1379 (ICN).

6. Cladonia palmicola Ahti \& Fleig, Napaea 11: 16. 1995. Fig. 6 
TALO PRIMÁRIO: persistente a evanescente, composto por esquâmulas, $0,5-0,8 \mathrm{~mm}$ de comprimento, $0,1-0,3 \mathrm{~mm}$ de largura, laciniadas, recortadas, sem sorédios, margens crenadas, sem rizinas; superfície superior lisa, suavemente lustrosa, esbranquiçadas a acinzentadas, sem pruína; superfície inferior aracnoide, branca; córtex $20-80 \mu \mathrm{m}$ de espessura, medula 50-190 $\mu \mathrm{m}$ de espessura; picnídios ausentes. TALO SECUNDÁRIO: 0,6-2,0 cm de altura, 0,6-1,0 mm de espessura, brancos amarelados a acinzentados, formando densas colônias, moderadamente ramificados, ramificações dicotômicas, anisotômicas, presentes principalmente na metade superior e próximas ao ápice, onde pequenos ramos (máximo de sete), 0,5-1,5 mm de comprimento, evidenciam a formação do funil, até $0,6 \mathrm{~mm}$ de diâmetro, acifosos, base não melanótica, perfurações presentes, axilas abertas formando um funil; superfície ecorticada, suavemente velosa, sem sorédios, densamente coberta por grânulos, 50-200 $\mu \mathrm{m}$ de diâmetro, esquâmulas laciniadas, crenadas, de tamanhos diminutos, $0,2-0,5 \mathrm{~mm}$ de comprimento, localizadas principalmente na metade inferior; medula $0-30$ $\mu \mathrm{m}$ de espessura, estereoma levemente amarelado, 50-110 $\mu \mathrm{m}$ de espessura, canal central ranhurado, 350-600 $\mu \mathrm{m}$ de diâmetro; discos himeniais ausentes; picnídios infrequêntes, apicais, marrom escuro a negros, globosos a subcilíndricos, mucilagem ausente, conídios ausentes.

Química: Testes de coloração: K+ amarelo vivo, C-, KC-, UV-. CCD: Ácido tamnólico.

Comentários: A espécie é bastante característica dentro do Supergrupo Perviae (ao qual pertence por apresentar axilas perfuradas e produzir ácido tamnólico) por ser a única que apresenta podécios com até $2,0 \mathrm{~cm}$ de altura, ecorticados, densamente cobertos por grânulos, presença de funil axilar evidenciado pelas curtas ramificações apicais e por produzir ácido tamnólico (Fleig et al. 1995).

Na descrição da espécie em Fleig et al. (1995) há apenas uma breve menção das axilas perfuradas ("pequeno cifo perfurado") e em Ahti (2000) as axilas são tratadas como fechadas. Entretanto, a análise de parátipos revelou que a maioria dos podécios de Cladonia palmicola possui perfuração axilar com até $0,6 \mathrm{~mm}$ de diâmetro, muitos deles formando funis, tornando o caráter muito importante na delimitação da espécie.

Cladonia subdelicatula Vain. ex Asahina é a espécie mais próxima a C. palmicola. Ambas possuem podécios ecorticados, com grânulos e esquâmulas presentes e produzem ácido tamnólico (Fleig et al. 1995). Porém, segundo Ahti (2000), C. subdelicatula possui podécios maiores que 1,5 $\mathrm{cm}$ de altura, podendo atingir até $7,0 \mathrm{~cm}$, com ápices subulados, não ramificados e sem a formação de funis axilares, enquanto que C. palmicola atinge a altura máxima de 2,0 $\mathrm{cm}$ e possui funis axilares evidentes.

De acordo com descrições de Vainio (1887) e de Ahti (2000), as espécies Cladonia chondrotypa Vain., C. granulosa (Vain.) Ahti e C. rhodoleuca Vain. assemelham-se a C. palmicola por possuírem os podécios pouco ramificados, granulosos, com axilas perfuradas e pela reação K+ amarelo vivo (ácido tamnólico). Contudo, as três possuem esquâmulas primárias digitadas ou lobadas e podécios maiores que 2,0 cm de altura, chegando a $10,0 \mathrm{~cm}$ em C. granulosa, enquanto que C. palmicola tem esquâmulas primárias laciniadas e podécios menores que 2,0 cm de altura (Ahti 2000).

Distribuição: Segundo Ahti (2000), Cladonia palmicola ocorre desde o nível do mar até 800 metros de altitude. É citada somente para o Uruguai (Ahti 2000) e para o Brasil, no estado do RS (Fleig et al. 1995). Esta é a primeira citação da espécie para Santa Catarina e amplia o limite setentrional da mesma.

Habitat: Foi encontrada somente em restinga, em área bem iluminada e sobre solo arenoso na base da palmeira Butia sp. Fleig et al. (1995) também citaram que os espécimes coletados de C. palmicola no Rio Grande do Sul estavam sobre restos vegetais de Butia capitata (Mart.) Becc., evidenciando uma possível predileção de substrato.

Espécimes examinados: BRASIL. Santa Catarina: Laguna, restinga, $28^{\circ} 24^{\prime} \mathrm{S}, 48^{\circ} 47^{\prime} \mathrm{O}, 09 / \mathrm{III} / 2009$, E. Gumboski $752 a$ (UPCB).

Espécimes adicionais examinados: BRASIL. Rio Grande do Sul: Torres, Butiazal, 07/VIII/1989, M. Fleig 3502 (ICN, parátipo); Morrinhos do Sul, 25/V/1993, M. Fleig 5844 (ICN, parátipo).

7. Cladonia polystomata Ahti \& Sipman, Fl. Neotrop., Monogr. 78: 294. 2000.

Fig. $7-8$

TALO PRIMÁRIO: evanescente, composto por esquâmulas, $0,7-3,6 \mathrm{~mm}$ de comprimento, $0,3-0,7 \mathrm{~mm}$ de largura, laciniadas, recortadas, sem sorédios, margens lisas a crenadas, sem rizinas; superfície superior lisa, lustrosa, esbranquiçada a esverdeada, sem pruína; superfície inferior aracnoide, branca; córtex 20-70(-90) $\mu \mathrm{m}$ de espessura, medula 30-50(-90) $\mu \mathrm{m}$ de espessura; picnídios ausentes. TALO SECUNDÁRIO: $0,6-2,5 \mathrm{~cm}$ de altura, $0,6-1,2 \mathrm{~mm}$ de espessura, esbranquiçados a cinza amarelado, pouco ramificado, em geral com até cinco ramificações laterais curtas, ápices subulados a capitados, acifoso, base não melanótica, perfurações presentes no ápice formando um funil com até 2,0 mm de diâmetro, muitas vezes com ramos marginais; superfície lisa e levemente sulcada, principalmente ecorticada, porém com córtex podendo ocorrer em algumas partes, distribuído aleatoriamente, principalmente em talos pouco desenvolvidos, sem sorédios e grânulos, com muitas esquâmulas ao longo do podécio, laciniadas, recortadas ou não, até $2,3 \mathrm{~mm}$ de comprimento; córtex quando presente até $20 \mu \mathrm{m}$ de espessura, medula $0-50(-200) \mu \mathrm{m}$ de espessura, estereoma esbranquiçado, 80-170 $\mu \mathrm{m}$ de espessura, canal central suavemente papilado, $500-1000 \mu \mathrm{m}$ de diâmetro; discos himeniais comuns, apicais, dispondo-se em aglomerados, marrons a negros, pequenos, até $0,5 \mathrm{~mm}$ de diâmetro, ascósporos fusiformes, $10-12 \times 3-4 \mu \mathrm{m}$; picnídios frequentes, laterais e apicais, marrons a negros, cilíndricos, conídios falciformes, 5-6 $\times 1 \mu \mathrm{m}$. 

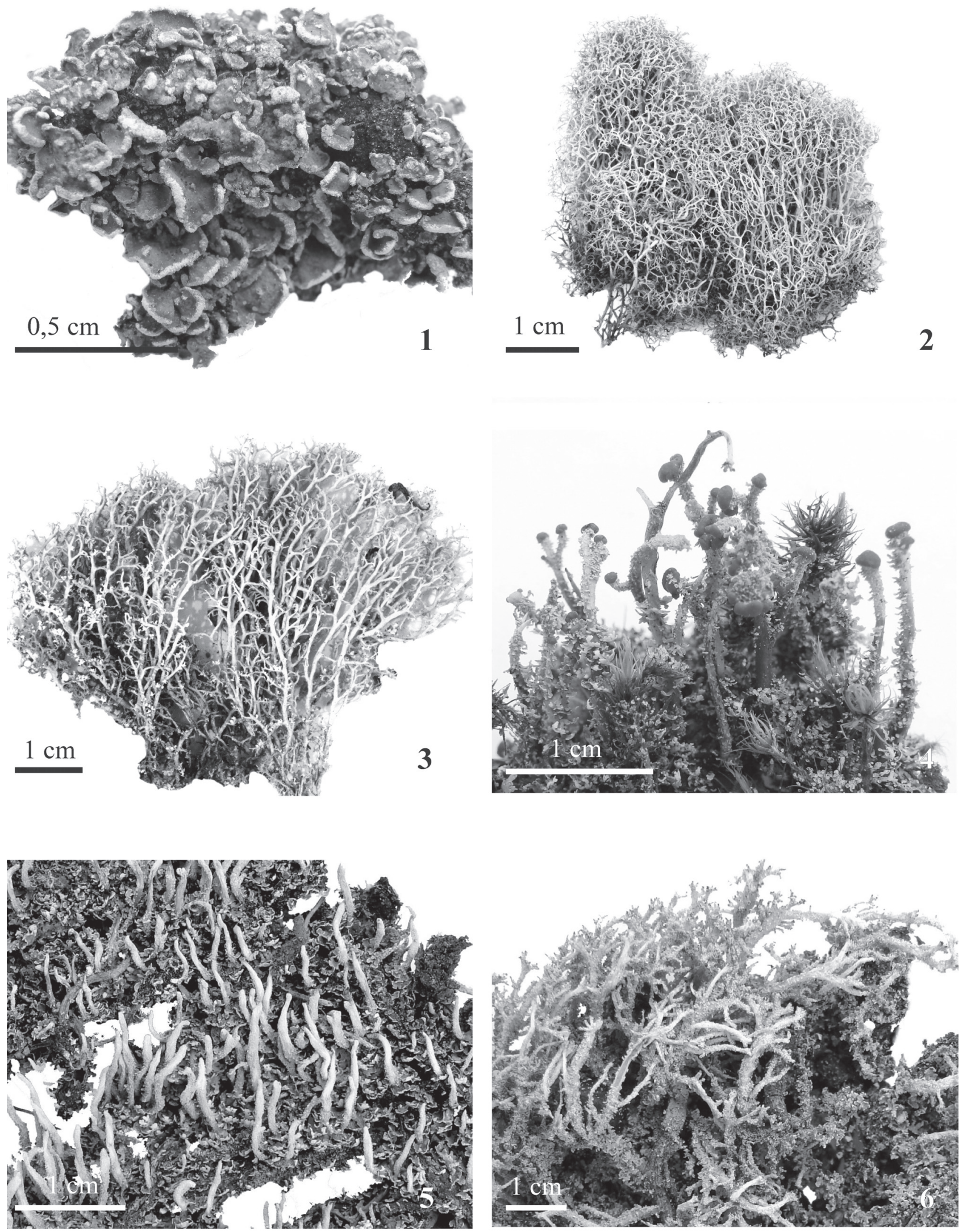

Figura 1-6. Espécies de Cladonia (Cladoniaceae, Ascomycota). 1. Cladonia ahtii S. Stenroos (E. Gumboski 785). 2. Cladonia confusa R. Sant. (M. Dal-Forno 542). 3. Cladonia crispatula (Nyl.) Ahti (E. Gumboski 753). 4. Cladonia didyma (Fée) Vain. (E. Gumboski \& S. Eliasaro 1574). 5. Cladonia macilenta Hoffm. (E. Gumboski \& F. Beilke 1842). 6. Cladonia palmicola Ahti \& Fleig (E. Gumboski 752a). 
Química: Testes de coloração: K+ amarelo vivo, C-, KC-, UV-. CCD: Ácido tamnólico e uma substância não identificada com Rf C aproximado de 68.

Comentários: Cladonia polystomata é caracterizada pelo podécio pouco ramificado, principalmente ecorticado, esquamuloso, sem grânulos e sorédios, axilas abertas gerando um funil conspícuo e por produzir ácido tamnólico (Ahti 2000).

Esta espécie pode ser facilmente confundida com $C$. sphacelata por ambas apresentarem podécios corticados, ao menos em partes, ausência de grânulos e sorédios, presença de muitas esquâmulas, e por produzirem ácido tamnólico (embora inconstante em C. sphacelata). Contudo, C. sphacelata possui o podécio mais delgado, continuamente corticado e com axilas geralmente fechadas, enquanto que $C$. polystomata possui o podécio mais robusto com a superfície apresentando poucas áreas corticadas e as axilas perfuradas geralmente formando funis conspícuos.

Segundo Vainio (1887), Cladonia squamosa também é similar a C. polystomata por apresentar o podécio principalmente ecorticado, esquamuloso e com axilas perfuradas. Contudo, enquanto C. squamosa apresenta grânulos ao longo do podécio, $C$. polystomata não forma grânulos e apresenta o podécio mais corticado que na primeira (Ahti 2000), sendo ainda que os espécimes de C. squamosa presentes na área de estudo não apresentaram ácido tamnólico.

Distribuição: De acordo com Ahti (2000), Cladonia polystomata ocorre desde o nível do mar até 2300 metros de altitude. É conhecida somente para a América do Sul, na Guiana, Venezuela e no Brasil, sendo citada para os estados do AM, MG, PR, RJ, SC e SP (Ahti 2000).

Habitat: Foi encontrada tanto em restingas quanto em costões rochosos, em áreas pouco sombreadas a bem iluminadas, sobre solo arenoso, galhos caídos ou sobre fina camada de sedimentos sobre rocha. Forma colônias esbranquiçadas a acinzentadas, geralmente conspícuas e comumente entremeadas com podécios de Cladonia didyma, C. furfuracea e C. subradiata, raramente com C. sphacelata.

Espécimes selecionados examinados: BRASIL. Paraná: Guaraqueçaba, Ilha das Peças, restinga, $25^{\circ} 28^{\prime} \mathrm{S}, 48^{\circ}$ 17'O, 20/III/2010, E. Gumboski \& F. Beilke 1805 (UPCB); Paranaguá, Parque Estadual da Ilha do Mel, restinga, 25 31'S, 48 18'O, 27/VIII/2009, E. Gumboski \& S. Eliasaro $1549,1550,1555$ (UPCB), ibid., costão rochoso, $25^{\circ} 30^{\prime} \mathrm{S}$, 48 18'O, 27/VIII/2009, E. Gumboski \& S. Eliasaro 1617, 1618 (UPCB); Matinhos, Ilha das Tartarugas, costão ro-

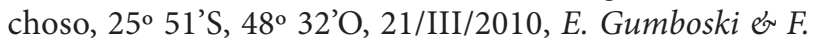
Beilke 1837 (UPCB). Santa Catarina: São Francisco do Sul, Morro João Dias, costão rochoso, $26^{\circ} 10^{\prime} \mathrm{S}, 48^{\circ} 31^{\prime} \mathrm{O}$, 05/III/2009, E. Gumboski 691 (UPCB), ibid., Parque Estadual do Acaraí, restinga, $26^{\circ} 15^{\prime} \mathrm{S}, 48^{\circ} 31^{\prime} \mathrm{O}, 17 / \mathrm{III} / 2009$, E. Gumboski 858, 866, 907 (UPCB); Imbituba, Praia de Itapirubá, costão rochoso, $28^{\circ} 20^{\prime} \mathrm{S}, 48^{\circ} 42^{\prime} \mathrm{O}, 19 / \mathrm{III} / 2010$, E. Gumboski \& F. Beilke 1761 (UPCB).
8. Cladonia sphacelata Vain., Acta Soc. Fauna Fl. Fenn. 4: 456. 1887.

Fig. 9

TALO PRIMÁRIO: persistente, composto por esquâmulas, $0,3-0,5 \mathrm{~mm}$ de comprimento, $0,2-0,5 \mathrm{~mm}$ de largura, laciniadas, recortadas, sem sorédios, margem lisa a crenada, rizinas comumente presentes, até $0,8 \mathrm{~mm}$ de comprimento, esbranquiçadas a negras; superfície superior lisa, lustrosa, esverdeada, sem pruína; superfície inferior suave a distintamente aracnoide, branca, às vezes pardacenta próximo a base. TALO SECUNDÁRIO: até $6,0 \mathrm{~cm}$ de altura, $0,4-1,8 \mathrm{~mm}$ de espessura, geralmente esverdeado, às vezes verde esbranquiçado, moderadamente ramificado, dicotômico a raramente tricotômico ou tetracotômico, podendo apresentar aspecto dorsiventral devido ao fato de parte dos podécios se projetarem horizontalmente, ápices subulados a capitados, acifosos, base não melanótica, perfurações principalmente ausentes, inconspícuas quando presentes, até $0,8 \mathrm{~mm}$ de diâmetro; superfície lisa, principalmente corticada, apresentando espaços ecorticados, em talos mais robustos as áreas ecorticadas são mais distintas, sem sorédios e grânulos, coberto por muitas esquâmulas laciniadas, recortadas, até $2,2 \mathrm{~mm}$ de comprimento, às vezes dispostas de tal forma que dão característica dorsiventral ao podécio, presença de rizomorfos em algumas; córtex (0-)20-40 $\mu \mathrm{m}$ de espessura, medula 30-90 $\mu \mathrm{m}$ de espessura, estereoma hialino, 40-120 $\mu \mathrm{m}$ de espessura, canal central papilado, $650-1100 \mu \mathrm{m}$ de diâmetro; discos himeniais frequentes, apicais e laterais, dispostos em aglomerados, marrons, ascósporos ausentes; picnídios frequentes, apicais, enegrecidos, dolioliformes a alongados, mucilagem ausente, conídios ausentes.

Química: Testes de coloração: K-, C-, KC-, UV-. CCD: Ácidos barbático, didímico, esquamático, e aparentemente ácidos condidímico e subdidímico, além de uma substância não identificada com Rf C aproximado de 1 .

Comentários: De acordo com Ahti (2000), Cladonia sphacelata é caracterizada pelo podécio moderadamente ramificado, com superfície lisa, lustrosa, principalmente corticada, esquamulosa, sem sorédios, sem grânulos e com axilas geralmente fechadas.

É facilmente confundida com C. polystomata por ambas possuírem podécio, ao menos em partes, corticado, esquamuloso, sem grânulos e sorédios, além de produzirem ácido tamnólico, embora esta substância seja inconstante em $C$. sphacelata (ver comentários em Cladonia polystomata).

A química de Cladonia sphacelata é bastante variada. Ahti (2000) cita três quimiotipos: o primeiro somente com ácido tamnólico ( $\mathrm{K}+$ amarelo vivo), o segundo somente com ácido esquamático (K-), e o terceiro com ácidos barbático, didímico e esquamático e outros compostos menores (K-). $\mathrm{Na}$ área de estudo somente foram encontrados exemplares com o terceiro padrão químico.

Distribuição: Ocorre desde o nível do mar até 2000 metros de altitude (Ahti 2000). É conhecida somente para 
o Brasil (Ahti 2000), nos estados de MG (Vainio 1887), PB, PR, PE, RJ, SC e SP (Ahti 2000). Ahti (comunicação pessoal) mencionou que outras citações mais antigas sobre esta espécie, a exemplo de Magnusson \& Zahlbruckner (1944) para o Havaí e Sipman \& Aptroot (1992) para a Guiana, são em sua maioria errôneas.

Habitat: Cladonia sphacelata foi encontrada somente no estado do Paraná, em restingas e costões, onde é localmente abundante. Geralmente ocorre em áreas bem iluminadas, sobre solo arenoso ou sobre fina camada de detritos sobre rocha. Os exemplares coletados em costões atingem o máximo de $1,0 \mathrm{~cm}$ de altura e $0,6 \mathrm{~mm}$ de espessura, mas mantém todas as outras características morfológicas, anatômicas e químicas pertinentes a espécie. Não foi comum encontrá-la entremeada com outras espécies de Cladonia, embora alguns podécios de $C$. polystomata e $C$. didyma tenham sido registrados.

Espécimes examinados: BRASIL. Paraná: Guaraqueçaba, Ilha das Peças, restinga, 26/X/2003, C. G. Donha 1350 (UPCB), ibid., restinga, $25^{\circ} 28^{\prime} \mathrm{S}, 48^{\circ} 17^{\prime} \mathrm{O}, 22 / \mathrm{III} / 2010$, E. Gumboski \& F. Beilke 1800, 1804, 1806 (UPCB); Paranaguá, Parque Estadual da Ilha do Mel, restinga 25 31'S, $48^{\circ}$ 18'O, 27/VIII/2009, E. Gumboski \& S. Eliasaro 1542,

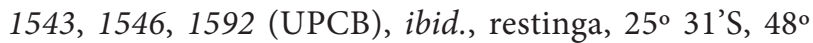
18'O, 27/VIII/2009, E. Gumboski \& S. Eliasaro 1594, 1597, 1606 (UPCB), ibid., costão rochoso, $25^{\circ} 32^{\prime} \mathrm{S}, 48^{\circ} 17^{\prime} \mathrm{O}, 27 /$ VIII/2009, E. Gumboski \& S. Eliasaro 1635, 1644 (UPCB).

\section{Cladonia squamosa Hoffm., Deutschl. Fl. 2: 125. 1796.} Fig. 10

TALO PRIMÁRIO: persistente, composto por esquâmulas, $1,0-2,0 \mathrm{~mm}$ de comprimento, $0,2-0,5 \mathrm{~mm}$ de largura, laciniadas, recortadas, margens lisas a crenadas, sem rizinas; superfície superior lisa, pouco lustrosa, esverdeada, sem pruína; superfície inferior suavemente aracnoide, branca; córtex 20-42 $\mu \mathrm{m}$ de espessura, medula 50-140 $\mu \mathrm{m}$ de espessura; picnídios ausentes. TALO SECUNDÁRIO: $4,0-12,0(-14,0) \mathrm{mm}$ de altura, $0,4-1,0 \mathrm{~mm}$ de espessura, verde acinzentado a amarronzado, simples, às vezes com dois a seis ramos curtos apicais, subulados, acifosos, base não melanótica, perfurações presentes formando um funil, às vezes bastante dilatadas, até $1,0 \mathrm{~mm}$ de diâmetro, geralmente rodeados por ramos curtos apicais; superfície ecorticada, córtex presente somente na base do podécio, levemente rugosa a lisa, sem sorédios, grânulos pouco globosos, distribuídos aleatoriamente, esquâmulas geralmente laciniadas, até $1,0 \mathrm{~mm}$ de comprimento, recortadas ou não, recobrindo normalmente da base até a metade do podécio; córtex $0-25(-75) \mu \mathrm{m}$ de espessura, medula 50-100(-150) $\mu \mathrm{m}$ de espessura, estereoma geralmente exposto, amarelo pálido a amarronzado, 150-300 $\mu \mathrm{m}$ de espessura, canal central papilado, $400-550 \mu \mathrm{m}$ de diâmetro; discos himeniais ausentes; picnídios frequentes, apicais, vermelho amarronzados, dolioliformes, mucilagem levemente vermelha, conídios ausentes.
Química; Testes de coloração: K-, C-, KC-, UV-. CCD: Ácido barbático, aparentemente ácido condidímico e ácido subdidímico.

Comentários: Segundo descrições em Vainio (1887) e Burgaz \& Ahti (2009), Cladonia squamosa é caracterizada pelo podécio simples a pouco ramificado, ecorticado, axilas abertas formando um funil com ramos curtos ao redor da abertura, sem sorédios, densamente cobertos por esquâmulas e grânulos.

Ahti (2000) e Burgaz \& Ahti (2009) mencionam que Cladonia squamosa possui uma variação morfológica bastante ampla mundialmente, podendo apresentar poucas esquâmulas no podécio, mas ainda assim, bem caracterizada por apresentar as axilas perfuradas. $\mathrm{Na}$ área de estudo todos os exemplares apresentaram o mesmo padrão morfológico e químico.

De acordo com Burgaz \& Ahti (2009) há dois quimiotipos para a espécie. O primeiro com ácido esquamático e traços de barbático e o segundo apenas com ácido tamnólico. Ahti (2000) inclui um quimiotipo que produz apenas ácido barbático e que é conhecido somente para a região de Valdivia, no Chile e para a Argentina. Todos os exemplares da área de estudo produzem ácido barbático e outros compostos menores, representando um novo quimiotipo para a espécie.

Cladonia polystomata é similar C. squamosa por possuir o podécio principalmente ecorticado, esquamuloso e com axilas perfuradas (ver comentário em Cladonia polystomata).

Distribuição: Ocorre desde o nível do mar até 4500 metros de altitude (Ahti 2000). Cosmopolita, ocorrendo inclusive na Antártica (Øvstedal \& Smith 2001), é conhecida para a Oceania (Vainio 1887), Ásia (Nylander 1900), Europa (Crombie 1883), África (Vainio 1887), América do Norte (Fulford 1937), América Central (Müller 1893) e América do Sul, na Argentina (Müller 1878), Bolívia (Flakus et al. 2008), Chile (Crombie 1876), Colômbia, Equador, Peru, Venezuela (Ahti 2000) e Brasil (Vainio 1887). É citada para os estados do PA, RJ (Vainio 1887), SC e SP (Ahti 2000). Esta é a primeira citação da espécie para o estado do Paraná.

Habitat: Embora Ahti (2000) tenha mencionado que Cladonia squamosa é raramente encontrada ao nível do mar, na área de estudo foram encontradas pequenas colônias tanto em restingas quanto em costões rochosos, porém, nunca de forma conspícua. Principalmente presente em locais bem iluminados e raramente associada com outras espécies, tais como Cladonia didyma e C. subradiata.

Espécimes examinados: BRASIL. Paraná: Paranaguá, Parque Estadual da Ilha do Mel, restinga, 25 $31^{\prime} \mathrm{S}, 48^{\circ}$ 18'O, 27/VIII/2009, E. Gumboski \& S. Eliasaro 1565, 1572, 1573 (UPCB), ibid., costão rochoso, $25^{\circ} 30^{\prime} \mathrm{S}, 48^{\circ} 18^{\prime} \mathrm{O}, 27 /$ VIII/2009, E. Gumboski \& S. Eliasaro 1621 (UPCB). Santa Catarina: Bombinhas, Praia de Mariscal, costão rochoso, $26^{\circ} 13^{\prime} \mathrm{S}, 48^{\circ} 29^{\prime} \mathrm{O}, 19 / \mathrm{II} / 2010$, E. Gumboski \& F. Beilke 1737 (UPCB); Laguna, Praia da Galheta, costão rochoso, $28^{\circ} 33^{\prime} \mathrm{S}$, $48^{\circ}$ 47’O, 18/II/2010, E. Gumboski \& F. Beilke 1783 (UPCB). 

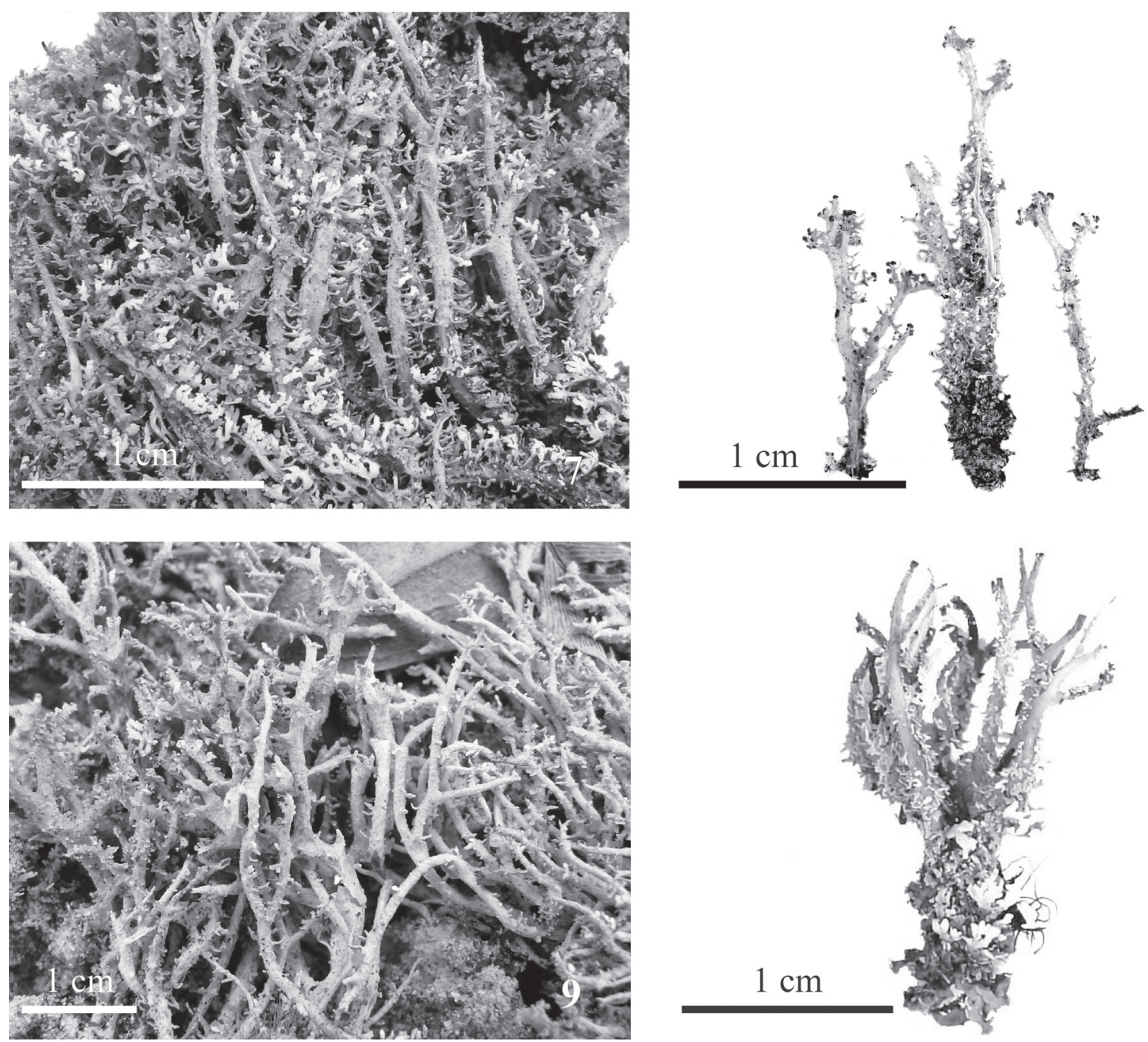

Figura 7-10. Espécies de Cladonia (Cladoniaceae, Ascomycota). 7-8. Cladonia polystomata Ahti \& Sipman (E. Gumboski \& F. Beilke 1805). 9. Cladonia sphacelata Vain. (E. Gumboski \& F. Beilke 1806). 10. Cladonia squamosa (Scop.) Hoffm. (E. Gumboski \& S. Eliasaro 1621).

\section{Agradecimentos}

Os autores agradecem profundamente a Dra. Ana Rosa Burgaz, Dra. Luciana da Silva Canêz, Dr. Adriano Afonso Spielmann, Dr. Marcelo Pinto Marcelli, Dr. Michel Navarro Benatti e Dr. Sammuel Hammer pelo envio de bibliografias importantes. À Dra. Soili Stenroos e ao Dr. Teuvo Ahti pelas bibliografias enviadas e discussões sobre algumas espécies. Aos dois revisores anônimos pelas importantes correções e sugestões. Aos curadores dos herbários ICN e SP pelo empréstimo dos espécimes solicitados. Aos biólogos Alice da Cruz Lima Gerlach, Flávio Beilke e Leandro Francisco de Oliveira pelo auxilio em coletas. Aos órgãos ambientais estaduais FATMA (Fundação do Meio Ambiente) e IAP (Instituto Ambiental do Paraná) pelas licenças de coletas concedidas. Emerson Luiz Gumboski agradece a CAPES (Coordenadoria de Aperfeiçoamento do Pessoal do Ensino Superior) pela concessão de bolsa de Mestrado.

\section{Referências bibliográficas}

Ahti, T. 1961. Taxonomic studies in reindeer lichens (Cladonia, subgenus Cladina). Annales Botanici Societatis Zoologicae Botanicae Fennicae 'Vanamo' 32(1): 1-160.

Ahti, T. 1977. The Cladonia gorganina group and C. gigantea in East Africa. Lichenologist 9: 1-15.

Ahti, T. 2000. Cladoniaceae. Flora Neotropica 78: 1-362.

Ahti, T. \& Hammer, S. 2002. Cladonia. Pp. 131-158. In: Nash, T.H.; Ryan, B.D.; Gries, C.\& Bungartz, F. (Eds.). Lichen Flora of the Greater Sonoran Desert Region. I. Lichens Unlimited. Tempe, Arizona State University.

Ahti, T. \& Kashiwadani, H. 1984. The lichen genera Cladia, Cladina, and Cladonia in southern Chile. Pp. 125-151. In: Inoue, H. (Ed.): Studies on Cryptogams in Southern Chile. Tokyo, Kenseisha Ltd.

Ahti, T. \& Marcelli, M. P. 1995. Taxonomy of the Cladonia verticillaris complex in South America. In: Farkas, E.E.; Lücking, R. \& Wirth, V. (Eds.). Scripta Lichenologica - Lichenological Papers Dedicated to Antonín Vezda. Bibliotheca Lichenologica 58: 5-26.

Ahti, T.; Stenroos, S. \& Xavier Filho, L. 1993. The lichen family Cladoniaceae in Paraiba, Pernambuco and Sergipe, Northeast Brazil. Tropical Bryology 7: 55-70. 
Benatti, M.N. 2005. Os gêneros Canomaculina, Parmotrema e Rimelia (Parmeliaceae, Ascomycetes) no litoral centro-sul do estado de São Paulo. Dissertação de Mestrado. Instituto de Botânica, São Paulo.

Brodo, I.M., Sharnoff, S.D. \& Sharnoff, S. 2001. Lichens of North America, New Haven, Yale University Press.

Burgaz, A.R. \& Ahti, T. 2009. Cladoniaceae. Flora Liquenológica Ibérica. v. 4. Madrid, Sociedad Española de Liquenología.

Calvelo, S. \& Liberatore, S. 2002. Catálogo de los líquenes de la Argentina. Kurtziana 29(2): 7-170.

Christensen, S.N. 1987. Morphological and chemical variation in the Cladonia macilenta/bacillaris aggregate in Denmark. Lichenologist 19: 61-69.

Crombie, J.M. 1876. On the Lichens collected by Prof. R.O. Cunningham in the Falkland Islands, Fuegia, Patagonia and the Island of Chiloe during the voyage of H.M.S. Nassau 1867-1869. The Journal of the Linnean Society. Botany 15: 222.

Crombie, J. M. 1883. Enumeration of the British Cladoniei. Grevillea 11: $111-115$.

Culberson, C.F. \& Ammann, K. 1979. Standard method zur Dünnschichtchomatographie von Flechtensubstanzen. Herzogia 5: 1-24.

Doidge, E.M. 1950. The South African fungi and lichens to the end of 1945. Bothalia 5: 1-1094.

Elix, J.A. \& Ernst-Russell, K.D. 1993. A Catalogue of Standardized Thin Layer Chromatographic Data and Biosynthetic Relationships for Lichen Substances. $2^{\text {nd }}$ ed. Camberra, Australian National University Camberra.

Flakus, A.; Ahti, T.; Kukwa, M.; Wilk, K. 2008. New and interesting records of Cladonia and their lichenicolous fungi from the Andean cloud forest in Bolivia. Annales Botanici Fennici 45: 448-454.

Fleig, M., Ahti, T. \& Stenroos, S. 1995. A família Cladoniaceae (liquens) no Rio Grande do Sul, Brasil. Napaea 11: 1-29.

Fulford, M. 1937. Some Cladoniae From Southwestern Ohio.Cladoniae from Clermont, Brown, and Adams Counties. Ohio Journal of Science 37: 295-300.

Grassi, M.M. 1950. Contribucion al catalogo de liquenes argentinos, I. Lilloa 24: 5-296.

Gumboski, E.L. \& Eliasaro, S. 2011a. Cladonia litoralis (Cladoniaceae), a new species from southern Brazil. The Bryologist 114(4): 665-667.

Gumboski, E.L. \& Eliasaro, S. 2011b. Checklist of lichenized fungi of Santa Catarina State (Brazil). Mycotaxon 115: 535.

Macoun, J. 1902. Catalogue of the Canadian plants. Part VII -Lichenes and Hepaticae. Ottawa, Government Printing Bureau.

Magnusson, A.H. \& Zahlbruckner, A. 1944. Hawaiian lichens. II. The families Lecideaceae to Parmeliaceae. Arkiv för Botanik 31A(6): 1-109.

Marcelli, M.P. 1990. Líquens das Restingas e Manguezais da Ilha do Cardoso. I. Pp. 382-392. In: II Simpósio de Ecossistemas da Costa Sul e Sudeste Brasileira: Estrutura, Funçao e Manejo. Aguas de Lindóia, Estado de Sao Paulo.

Marcelli, M.P. 1992. Ecologia Liquênica nos Manguezais do Sul-Sudeste Brasileiro. Bibliotheca Lichenologica 47: 1-288.

Marcelli, M.P. 1998. History and current knowledge of Brazilian lichenology. Pp. 25-45. In: Marcelli, M.P.\& Seaward, M.R.D. (Eds.). Lichenology in Latin America: History, current knowledge and applications. São Paulo, CETESB.

Marcelli, M.P. \& Benatti, M.N. 2008. Espécies de Parmotrema (Parmeliaceae, Ascomycetes liquenizados) com rizinas dimórficas do litoral centro-sul do Estado de São Paulo. Hoehnea 35(2): 171-183.

Marcelli, M.P. \& Benatti, M.N. 2010a. Espécies de Parmotrema (Parmeliaceae, Ascomycota) do litoral centro-sul do Estado de São Paulo II. Grupos químicos norstíctico e salazínico. Acta Botanica Brasilica 24(1): 153-168.

Marcelli, M.P. \& Benatti, M.N. 2010b. Espécies de Parmotrema (Parmeliaceae, Ascomycetes liquenizados) com ácidos graxos ou atranorina medulares do litoral centro-sul do Estado de São Paulo. Hoehnea 37(1): 117-129
Marcelli, M.P.; Benatti, M.N. \& Elix, J.A. 2008. New species of Parmotrema containing protocetraric or stictic acids from the coast of São Paulo State, southeastern Brazil. Mycotaxon 105: 235-248.

Müller [Argoviensis], J. 1878. Lichenologische Beiträge. Flora 61: 482-492. Müller [Argoviensis], J. 1884. Lichenologische Beiträge. Flora 67: 613-621.

Müller [Argoviensis], J. 1889. Lichenes Spegazziniani In Staten Island, Fuegia Et In Regione Freti Magellanici Lecti. Nuovo Giornale Botanico Italiano 21: 35-54.

Müller [Argoviensis], J. 1891a. Lichenes Catharinenses a cl. E. Ule in Brasilia prov. Santa Catharina lecti. Hedwigia 30: 235-243.

Müller [Argoviensis], J. 1891b. Lichenes Schenckiane a cl. Dr. H. Schenck, Bonnensi, in Brasiliae orientalis prov. Santa Catharina, Paraná, Rio de Janeiro, Minas Geraes et Pernambuco lecti. Hedwigia 30: 219-234.

Müller [Argoviensis], J. 1893. Lichenes, in Th. Durand et H. Pittier, Primitae florae Costaricensis. Séconde énumération. Bulletin de la Société royale de Botanique de Belgique 32: 122-173.

Nylander, W. 1869. Lichenes In Brasilia A Glaziou Collecti. Flora 52: 117-126.

Nylander, W. 1900. Lichenes Ceylonenses Et Additamentum Ad Lichenes Japoniae. Acta Societatis Scientiarum Fennicae 26: 1-33.

Osorio, H.S. 1997. Contribution to the lichen flora of Brazil. XXXIV. Lichens from Laguna, Santa Catarina State. Comunicaciones Botánicas del Museo de Historia Natural de Montevideo 6(108): 1-4.

Osorio, H.S. \& Arbelo Martins, C.S. 1980. Contribution to the lichen flora of Brazil V. Three interesting records from Rio Grande do Sul. Phytologia 46: 229-230.

Osorio, H.S. \& Fleig, M. 1982. Contribution to the lichen flora of Brazil IX. Lichens from the Municipality of Torres, Rio Grande do Sul State. Mycotaxon 14: 347-350.

Osorio, H.S. \& Fleig, M. 1986. Contribution to the lichen flora of Brazil XVIII. Lichens from Itaimbezinho, Rio Grande do Sul State. Comunicaciones Botanicas del Museo de Historia Natural de Montevideo 4(75): 1-8.

Øvstedal D.O. \& Smith R.I.L. 2001. Lichens of Antarctica and South Georgia. A Guide to their Identification and Ecology. Studies in Polar Research, Cambridge, Cambridge University Press.

Santesson, R. 1942. The South American Cladinae. Arkiv för Botanik 30A(10): 1-27.

Sipman, H.J.M. 1990. Lichenotheca Latinoamericana a museo botanico berolinensi edita, fasciculum primum. Willdenowia 19: 543-551.

Sipman, H.J.M. 1993. Lichens from Mount Kinabalu. Tropical Bryology 8: 281-314.

Sipman, H.J.M. \& Aptroot, A. 1992. Results of a botanical expedition to Mount Roraima, Guyana. II. Lichens. Tropical Bryology 5: 79-108.

Spielmann, A.A. 2006. Checklist of lichens and lichenicolous fungi of Rio Grande do Sul (Brazil). Caderno de Pesquisa Série Biologia 18(2): 7-125.

Stenroos, S. 1989. Taxonomic revision of the Cladonia miniata group. Annales Botanici Fennici 26: 237-261.

Stenroos, S.; Myllys, L.; Thell, A. \& Hyvönen, J. 2002a. Phylogenetic hypotheses: Cladoniaceae, Stereocaulaceae, Baeomycetaceae, and Icmadophilaceae revisited. Mycological Progress 1(3): 267-282.

Stenroos, S., Hyvonen, J., Myllys, L., Thell, A. \& Ahti, T. 2002b. Phylogeny of the genus Cladonia s.lat. (Cladoniaceae, Ascomycetes) inferred from molecular, morphological, and chemical data. Cladistics 18: 237-278.

Swinscow, T.D.V. \& Krog, H. 1988. Macrolichens of East Africa. London, British Museum.

Taylor, C.J. 1967. The lichens of Ohio. Part I. Foliose lichens. Columbia, The Ohio Biological Survey, The Ohio State University Press.

Taylor, C.J. 1968. The lichens of Ohio. Part II. Fruticose lichens. Columbia, The Ohio Biological Survey, The Ohio State University Press.

Vainio, E.A. 1887. Monographia Cladoniarum universalis. I. Acta Societatis Pro Flora Et Fauna Fennica 4: 1-509. 